\title{
JEJUNOGASTRIC INTUSSUSCEPTION - CASE SERIES REPORTING
}

SARKAR MAR

\begin{abstract}
Jejunogastric Intussusception is rare but potentially serious complication of gatrojejunostomy or gastrectomy requiring early diagnosis and prompt surgical intervention in acute form of the complication. Upper GI Endoscopy by a familiar person with this rare condition is diagnostic. The clinical picture of acute intestinal obstruction with haematemesis in the back ground of gastrectomy or gastrojejunostomy may make the illusive diagnosis definite and demand surgery to reduce morbidity and mortality of the patients. In our all the 4 cases Upper G I Endoscopy found to be diagnostic.
\end{abstract}

Keywords: Jejunogastric Intussusception, Upper GI Endoscopy, Acute intestinal obstruction.

(J Dhaka Med Coll. 2008; 17(2) : 134-137)

\section{Introduction}

Jejunogastric intussusception is a rare but potentially very serious complication of gastrectomy or gastroenterostomy described in 1941 by Bozzi ${ }^{1}$. About 200 cases have been reported since then ${ }^{1}$. A mortality of $10 \%$ to $50 \%$ has been reported. Emmergency endoscopy can put the correct diagnosis very soon. Early diagnosis and surgical intervention is required for the definite treatment. Threre is no medical treatment of jejunogastric intussusception. Three cases were were described who were admitted to the hospital with jejunogastric intussusception was subsequently diagnosed by emmergency endoscopy.

3 cases were encountered.

Case 1: A 70 yr old man presented with acute abdomen with vomiting followed by haematemesis 18 yrs after gastrojejunostomy for peptic ulcer disease. Physical examination revealed rounded mass at epigastrium. Endoscopy revealed a congested, cyanosed lobulated mass protruded through the stoma ultimately resection of the intussusceptum done by surgery.

Case 2: A 55 yr old man presented with sudden severe abdominal pain with vomiting and haematemesis $15 \mathrm{yr}$ after gastrojejunostomy for peptic ulcer disease. Physical examination revealed no mass or any other abnormality in abdomen. Upper GI Endoscopy shows the presence of lobulated congested mass through stoma and surgical reduction done and the patient become all right.

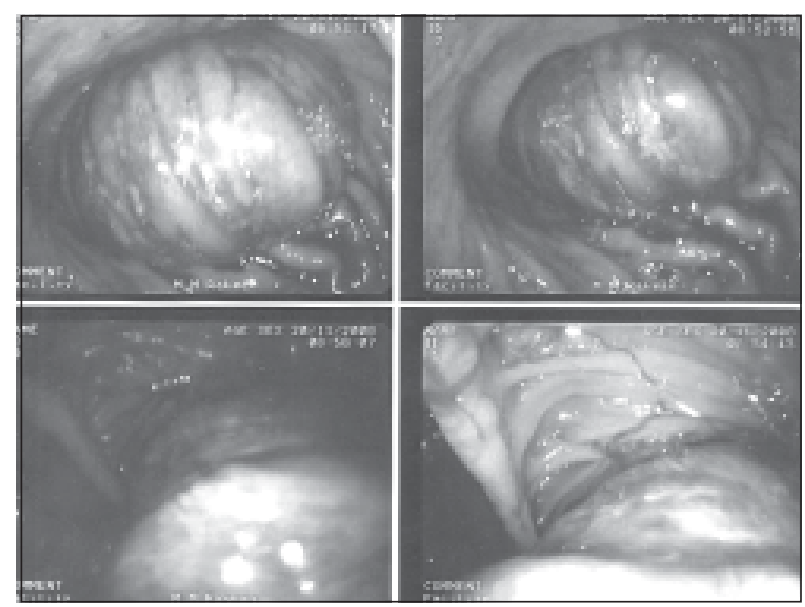

Fig.-1: Endoscopic Picture: Congested, cyanosed, lobulated, 3. mass through stoma

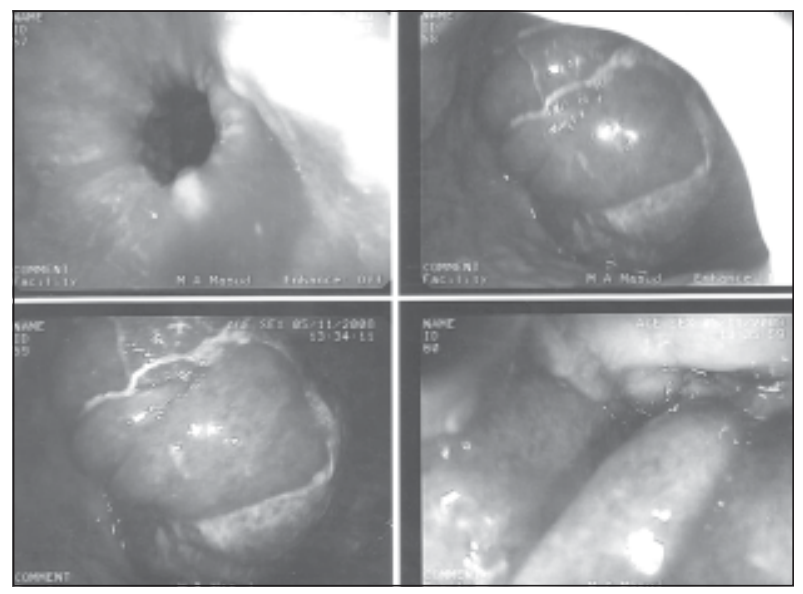

Fig.-2: Endoscopic pictures: Lobulated congested mass through stoma. 

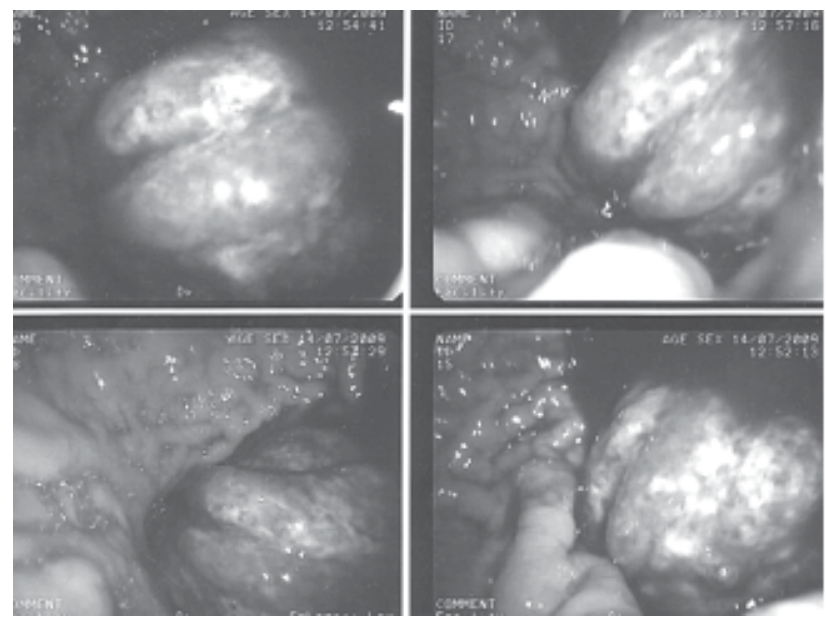

a) Lobulated mass protruded through stoma
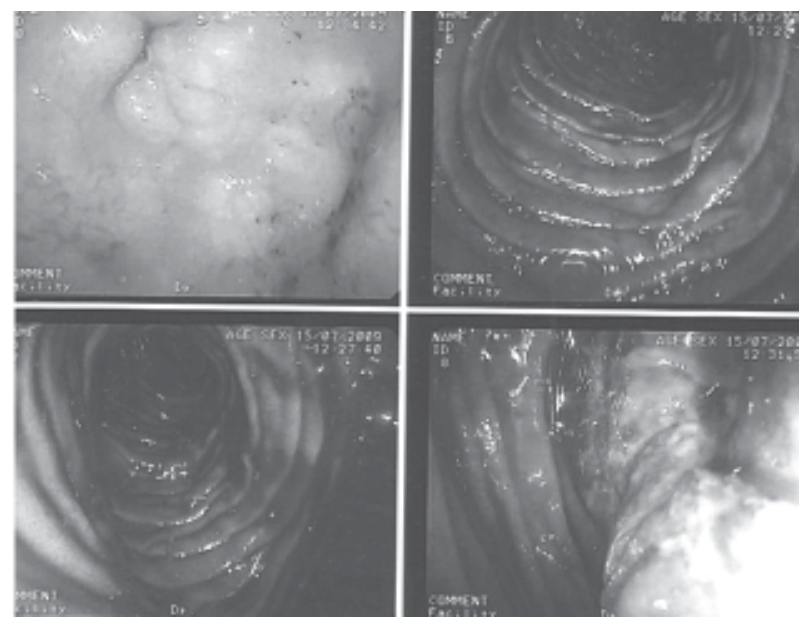

b) After 3 days Endoscopy shows intussusceptum moved more distally

Fig-3. Endoscopic picture

Case 3: A 70 yr old man presented with acute abdominal pain with vomiting of altered color fluid having a history of gastric operation $27 \mathrm{yr}$ back admitted in Dhaka medical college. He had two similar attacks in last 27 yrs after his gastric surgery. Physical examination revealed no mass or other abnormality in abdomen. Endoscopy shows lobulated mass protruding through stoma. Conservative therapy improved his previous attacks. In this attack at Dhaka Medical College he was kept on iv fluid, nasogastric suction and nothing by mouth and on iv antibiotic.

Endoscopic examination after 3 days also shows improvement of the situation and the intussusceptum moved much more distally. After 5 days the condition improved and the patient left the hospital.

\section{Discussion}

Jejunogastric intussusception is a rae but potentially serious complication of gastrojejunostomy and gastrectomy. Wolfer performed the first gastrjejunostomy in 1881 and 30 years later Bozzi reported jejunogastric intussusception first in $1914{ }^{1}$. Steber at 1917 reported another case in a 21 yr old lady with pregnancy at autopsy that died due to this complication. The 100th case was reported in $1955^{2}$. This complication after partial gastrectomy was first reported by Lundberg in $1922^{3}$. About 200 cases have reported till date. ${ }^{1}$ The incidence of jejunogastric intussusception is very low 3 per 2000 operations approximately after gastric operation. This complication most commonly observed after Billroth 11 but can complicate any gastric surgery including billroth 1 gastrectomy and total gastrectomy ${ }^{4}$. Aetiology is unclear.There are two theories, one is functional and another is mechanical .The most widely accepted one is the disordered motility with functional hyperperistalsis triggered by spasm or hyperacidity 5 . Mechanical factor include adhesion, long mesentry, sudden increased abdominal pressure. Polyps or neurofibromatosis have also been proposed as a factor for this condition. Jejunogastric intussusception can be classified into 3 groups ${ }^{6}$ as afferent loop Intussusception into stomach (16\%), efferent loop intussusception into stomach (74\%) and both loops Intussusception into stomach (10\%) .May present as an acute surgical emmergency or commonly as a chronic problem. May present from $1^{\text {st }}$ wk post operative to as late as $30 \mathrm{yrs}$. May both form mimic post gastrectomy syndrome. A high index susciption can avoid delay in diagnosis. Acute form present like proximal intestinal obstruction with sudden 
abdominal pain, nausea, vomiting, Lt hypochondriac palpable mass $(<50 \%)$ cases and haematemesis (sign of incurciration).

There is no sign of peritoneal irritation as lesion is intraluminal and Ileus is a late manifestation. The chronic form is difficult to diagnose and Present with nausea vomiting and interrmittent abdominal pain follows food and spontaneous reduction is usual in chronic form.

For diagnosis Upper GI Endoscopy should be the $1^{\text {st }}$ test which will allow direct visualization of the lesion ${ }^{7}$. Upper abdominal contrast study will show coil spring Jejunal filling diffect in stomach by barium 8 . Coronal $\mathrm{CT}$ is another excellent imaging modality for this condition. A plain $\mathrm{x}$ ray abdomen may also help showing a homogeneous density in the lt upper quadrant which represent small bowel in stomach ${ }^{9}$. Management depends on severity of the condition. Mortality rise with delay in operation this is $10 \%$ with in $48 \mathrm{hr}$ and rise upto $50 \%$ thereafter $^{10}$. Non operative management may help only when there is no evidence of vascular compromise, shock, haematemesis, peritoneal irritation or prolonged obstruction. There are lot of reports of abrupt deterioration and death when incarciration was neglected. Benificial result observed with sedation nasogastric suction and effect of the weight barium and fluoroscopic manipulation. Early post operative inussusception does not require surgical treatment. No report published about incurciration associated with early post operative period. Operative reduction alone is satisfactory in a patient who has had no previous difficulty. One case of recurrence after surgical reduction reported ${ }^{16 .}$

Revision of anastomsis means converting an antecolic anastomosis to retrocolic position or changing a Billroth 11 to Billroth 1 type anastomosis.

Local fixation is a simple and safe maneuver and should reduce mobility of the jejunum near the gastroenterostomy.
Emergency operation for incarcerated acute intussusception should be confined to reduction of the intussusception, resection of non viable bowel and stabilizing the loop by suturing it to adjacent mesentry of the colon.

\section{Conclusion:}

Jejunogastric Intussusception is a rare condition. Only about 200 hundred cases have been published after its $1^{\text {st }}$ description in 1914 . Endoscopy is certainly diagnostic by a person familiar with this cases. Our 4 cases were diagnosed by Endoscopy. There is no medical treatment and surgical intervention is the correct way of management where reduction, resection and revision of the anastomosis are done depending on the condition found during operation. Chronic intermittent form is benefited by conservative therapy.

\section{Refernces:}

1. Bozzi E. Annotation. Bull Acad Med 1914; 122: 3-4.

2. Irons $\mathrm{H} \mathrm{Jr}$, Lipin R: Jejunogastric intussusception following gastroenterostomy and vagotomy. Anals of Surgery 1955; 141: 541.

3 Mason L. Retrograde junogastric intussusception following gastrectomy. Archieves of Surgery 1960; 81: 485-91.

4. Conklin E, Merkwitz AM: Intussusception, a complication of gastric surgery. Surgery 1965; 57:480-885.

5. Robertson DS, Weder C. Acute jejunogastric intussusceotion Canadian Journal of Surgery 1968; 1: 210-14.

6. Shakman R. Jejunogastric intussusception. British Journal of Surgery 1940; 27: 475-80.

7. Budric TJ, Turner MA, Cho S.R: Retrograde Jejunogastric Intussusception. Rev Int Radio. 1981; 6(1): 21-4.

8. Devor D, Passaro E Jr. Jejunogastric intussusceptions: review of four casers diagnosisa nd management. Ann Surg 1956; 163: 93-96

9. Caudel ES, Lee ML Jr. Acute and chronic jejunogastric intussusceptions. 1955; 253: $635-40$

10. Leman, S.A: Jejunogastric intussusceeption, Rare Complication of operated stomach . Acta radiol 1948. 929: 383. 
11. Cameron, J.A.M and Mac Farlane, W.D: Intussusceeption of Jejunum into stomach Through a Gastro-enterostomy Stoma . British J. of Surgery 1935, 23:274.

12. Shiffman M, Rapport I: Intussusception following gastric resection. Am Surg 1966, 32: 715- 724 Pub med extract

13. Salem MH, CoffmanSE, Postlethwait RW: Retrograde intussusception at the gastrojejunal stoma . Ann Surg 1959, 150: $864-871$.
14. Lopez Mut JV, Cubells M, Campos S, Miranda V, Rivera P: Jejunogastric intussusception: a are complication. Abdominal imaging 1998, 23 :558559.

15. Wheatley MJ: Jejunogastric intussusception diagnosis and management. J Clin Gastroenterol 1989; 11: 452-4

16. Bettman RB, Baldwin RS. Retrograde intussusception of jejunum: Complication of gastrenterostomy. J Am Med Assoc. 1933; 100: 1228. 